\title{
Estudo das perdas de calor relacionadas a injeção de vapor e solvente C7 em reservatórios de óleo pesado
}

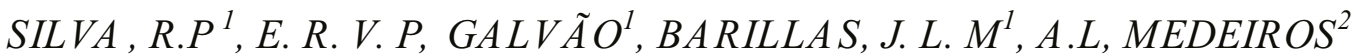 \\ 1 \\ Universidade Federal do Rio Grande do Norte, Departamento de Engenharia de \\ Petróleo \\ 2 Universidade Federal do Rio Grande do Norte, Departamento de Engenharia de \\ Materias
}

\begin{abstract}
RESUMO - Devido aos grandes desafios encontrados na indústria de petróleo, existe uma constante necessidade de aperfeiçoar métodos existentes, em especial os térmicos, para aumentar a produção. A recuperação térmica com adição de solvente permite um melhor aproveitamento do reservatório. Isso porque, o calor reduz a viscosidade de óleo, facilitando o seu deslocamento de forma significativa, enquanto o solvente promove uma diminuição da tensão interfacial entre os dois fluidos (água e óleo) promovendo a miscibilidade das mistura e aumentando a eficiência de deslocamento. O objetivo principal deste trabalho foi obter o máximo desempenho para o processo de injeção de vapor com solvente $\mathrm{C} 7$ na recuperação de óleos pesados e extra-pesados, através de um estudo numérico. Para tal finalidade, foi realizada uma análise da viabilidade de se injetar uma mistura de vapor e solvente e um estudo da sensibilidade do processo.
\end{abstract}

\section{INTRODUÇÃO}

Durante o processo de produção em um reservatório de petróleo, há uma dissipação da energia primária, causada pela descompressão dos fluidos do reservatório e pelas resistências encontradas pelos mesmos ao fluírem em direção aos poços de produção. Essas resistências são devidas, ou associadas, às forças viscosas e capilares presentes no meio poroso. O consumo de energia primária reflete-se principalmente no decréscimo da pressão do reservatório durante a sua vida produtiva, e consequente redução da produtividade dos poços (Rosa, 2006).

Devido às grandes quantidades de hidrocarbonetos retidas no reservatório após a exaustão da energia primária, foram desenvolvidos métodos de recuperação para obter uma quantidade adicional de óleo. Os métodos convencionais de recuperação (injeção de água e injeção de gás imiscivel) têm como finalidade única deslocar o óleo para fora dos poros da rocha, buscando-se um comportamento puramente mecânico. Mas, devido à alta viscosidade, nem sempre o óleo pode ser deslocado de maneira eficiente através desses métodos.

Assim, para a recuperação de óleos pesados, são aplicados os métodos térmicos de recuperação avançada de petróleo, principalmente a injeção de vapor pode ser empregada de maneira cíclica ou contínua. Na injeção contínua de vapor, o fluido é injetado continuamente, diferentemente da injeção cíclica. Enquanto na cíclica tanto a injeção como a produção ocorrem no mesmo poço, na injeção contínua os poços injetores e produtores são distintos. Em muitos campos de óleos pesados, a injeção de vapor cíclica precede a contínua, devido ao retorno mais rápido do investimento realizado no projeto e à melhoria na injetividade (Rodrigues, 2012). 
Atualmente, a injeção de vapor e solvente é o método de recuperação avançada utilizada para a extração de óleos pesados. No cenário da recuperação avançada, temos a injeção de vapor e solvente como uma combinação de um método térmico e um método miscivel. Para que o processo se torne mais eficiente, é necessário que o mínimo de calor seja perdido nos equipamentos de geração, nas linhas de superfície, nos poços de injeção e para as camadas subjacentes e sobrejacentes ao reservatório.

Neste trabalho, foi realizado um estudo numérico das perdas de calor relacionadas a injeção de vapor e solvente. Tal método consiste em injetar energia na forma de calor no reservatório, promovendo, assim, o aquecimento do óleo, a diminuição da sua viscosidade e o aumento da sua mobilidade no meio poroso, além de diminuir as tensões interfaciais devido a presença do solvente, altamente miscível com os hidrocarbonetos da reserva.

\section{Materias e Métodos}

\subsection{Ferram entas Computacionais}

Foram utilizados três módulos do simulador computacional da CMG (Computer Modelling Group Ltd.), versão 2012.10: Módulo WINPROP (Phase Behavior and Property Program), Módulo BUILDER (Pre-Processing Applications) e Módulo STARS (Steam, Thermal, and Advanced Processes Reservoir Simulator).

\subsection{Módulo WINPROP}

Ferramenta utilizada na construção do modelo de fluidos. O WINPROP (Phase Behavior and Property Program) pode ser utilizado para representar condições de reservatório ou de superfície, permitindo caracterizar de forma concisa sistemas de fluidos conhecidos por meio de equivalência ou ensaios de laboratório.

\subsection{Módulo BUILDER}

O BUILDER (Pre-Processing Applications) possibilitou o desenvolvimento do modelo de reservatório. Ele comporta todas as áreas dos dados fornecidos, inclui a criação e importação de malhas bidimensionais e tridimensionais, suas características, localização de poços, importação de dados de produção, de modelos de fluidos, condições iniciais e propriedades da rocha.

\subsection{Módulo STARS}

STARS (Steam, Thermal, and Advanced Processes Reservoir Simulator), um simulador trifásico que permite a inserção de múltiplos componentes, permitindo simular recuperações térmicas de óleo.

\subsection{Modelo Físico do Reservatório}

A configuração dos poços obedece ao padrão de malha five-spot invertido (um poço injetor no centro da malha e quatro poços produtores nos vértices. Com o objetivo de reduzir o tempo de 
simulação e considerando a simetria do sistema, foi utilizado, nos arquivos de dados, apenas 1/4 de 5spot, representado por um poço injetor e outro produtor. A Figura 1 mostra a representação esquemática do reservatório, cujas características físicas também estão listadas.

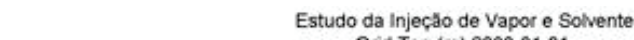
Grid Top (m) 2000-01-01

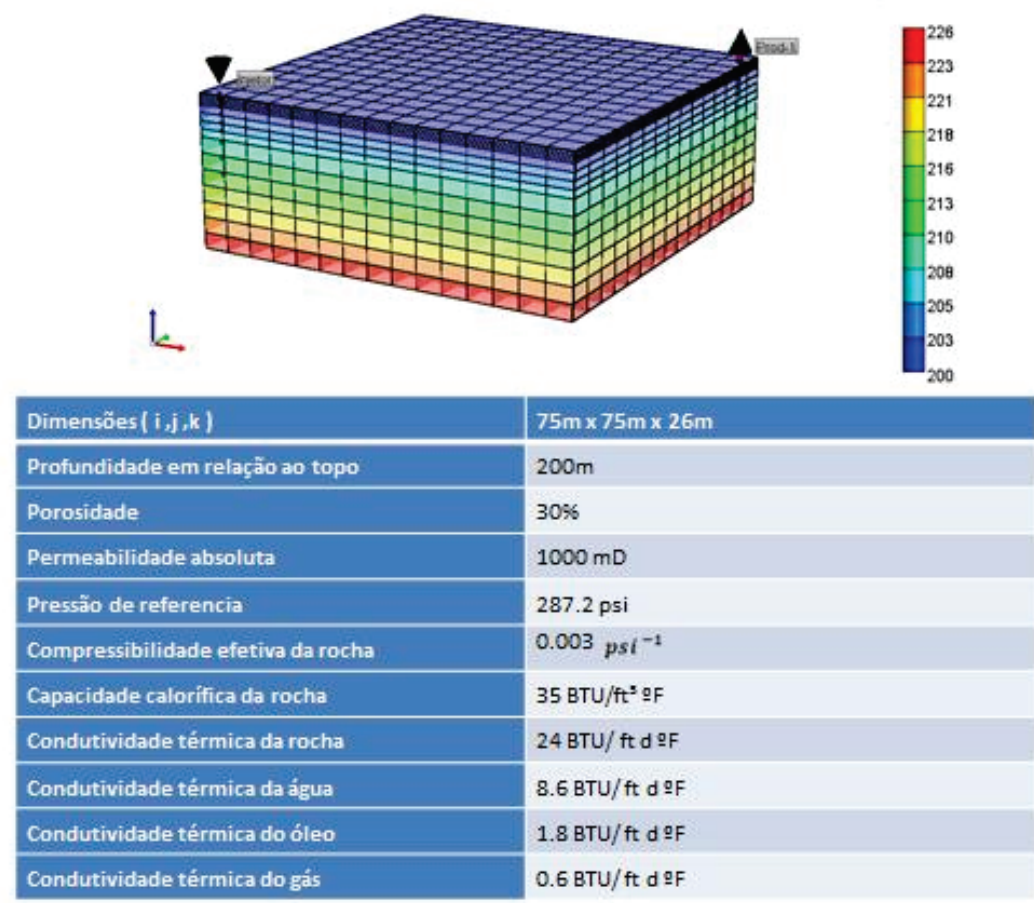

Figura 1: Representação física e principais propriedades do reservatório.

Inicialmente, foram simuladas 3 vazões $\left(25,35\right.$ e $50 \mathrm{~m}^{3} /$ dia) com 100\% de vapor. A partir dos resultados obtidos, foi escolhida a vazão que apresentou menor perda de calor e, a partir dela, foram adicionados $5 \%, 10 \%$ e $15 \%$ de solvente $C 7$.

\section{Resultados e Discussões}

As Figuras que compõe a Figura 2, a seguir, mostram os calores envolvidos na injeção de 25, 35 e $50 \mathrm{~m}^{3} /$ dia de somente vapor no reservatório. Foi considerada a entalpia inicial do reservatório (entalpia "in place"), a entalpia inserida pelo sistema a partir da injeção de vapor (entalpia injetada), a entalpia correspondente aos fluidos produzidos (entalpia produzida) e a entalpia perdida, como sendo a diferença entra a injetada e as demais entalpias citadas.

Observa-se que, à medida que aumentamos a vazão de injeção, aumentamos também a perda de calor para o as camadas adjacentes e sobrejacentes do reservatório. Esse resultado já era esperado, 
uma vez que, o aumento da vazão, implica em um aumento da entalpia injetada através do vapor no reservatório. Nesse sentido, com o objetivo de minimizar as perdas de calor e otimizar o processo, a vazão de $25 \mathrm{~m}^{3}$ /dia foi utilizada para o estudo das perdas de calor com adição de solvente

A Figura 3 ilustra as misturas de vapor e solvente que foram analisadas. Considerando a vazão constante de 25 m/dia de vapor, foram incrementados valores de 5\%, 10\% e 15\% que correspondem a fração de solvente na mistura. Essa escolha foi importante para não perder a sensibilidade do estudo, que visa avaliar como o solvente interfere nas perdas de calor. Em relação às porcentagens utilizadas, deve-se ao fato de que, estudos anteriores indicarem que o solvente deve ser utilizado em baixas concentrações, em virtude do seu custo e, também, à medida que sua quantidade aumenta na mistura, a quantidade de calor diminui, uma vez que a entalpia inserida no sistema através do solvente é menor, em virtude da sua capacidade calorifica ser menor do que a da água.
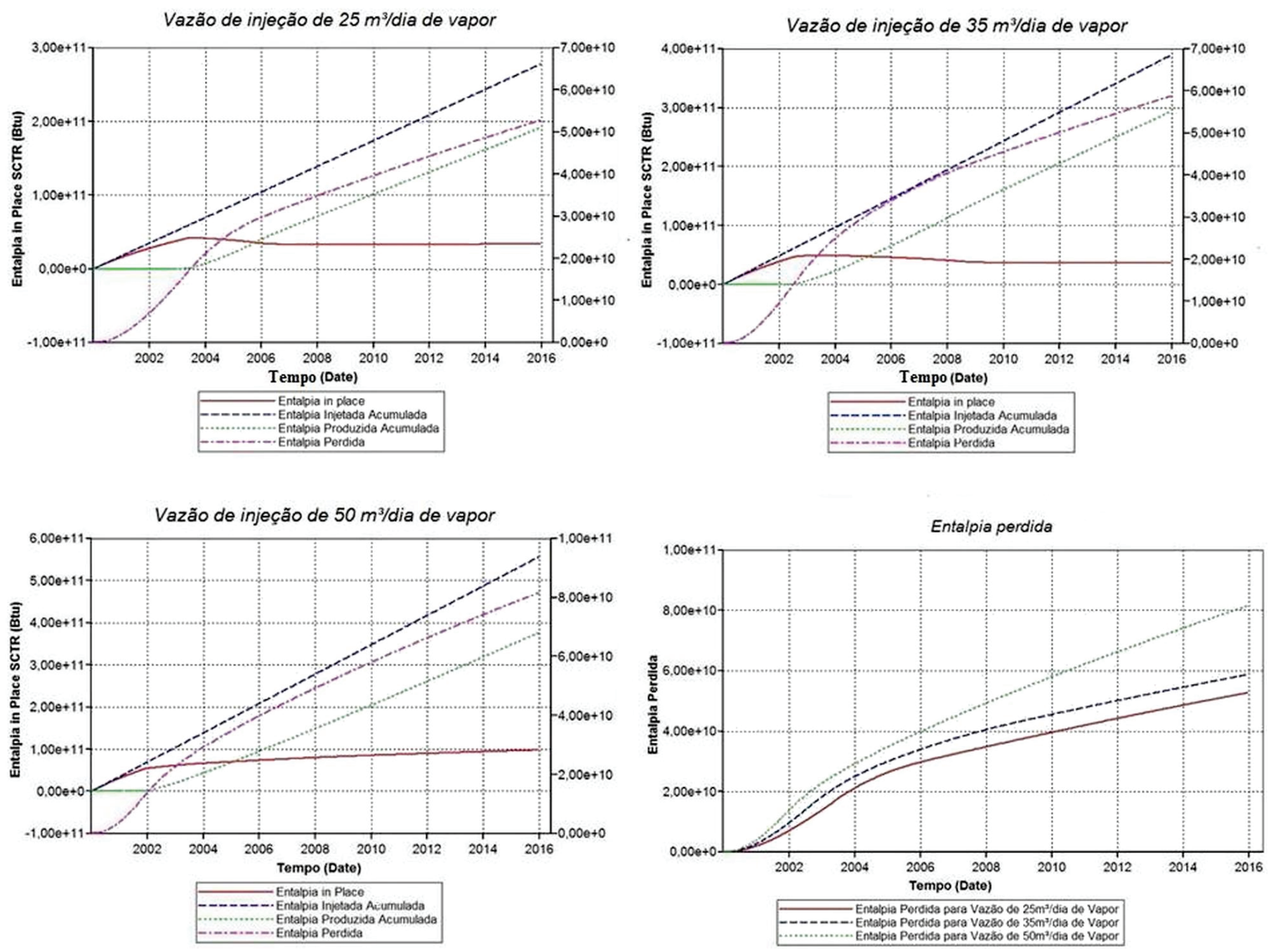

Figura 2: Entalpias envolvidas na injeção de diferentes vazões de vapor e entalpia perdida para cada 
vazão (figura do canto inferior direito).

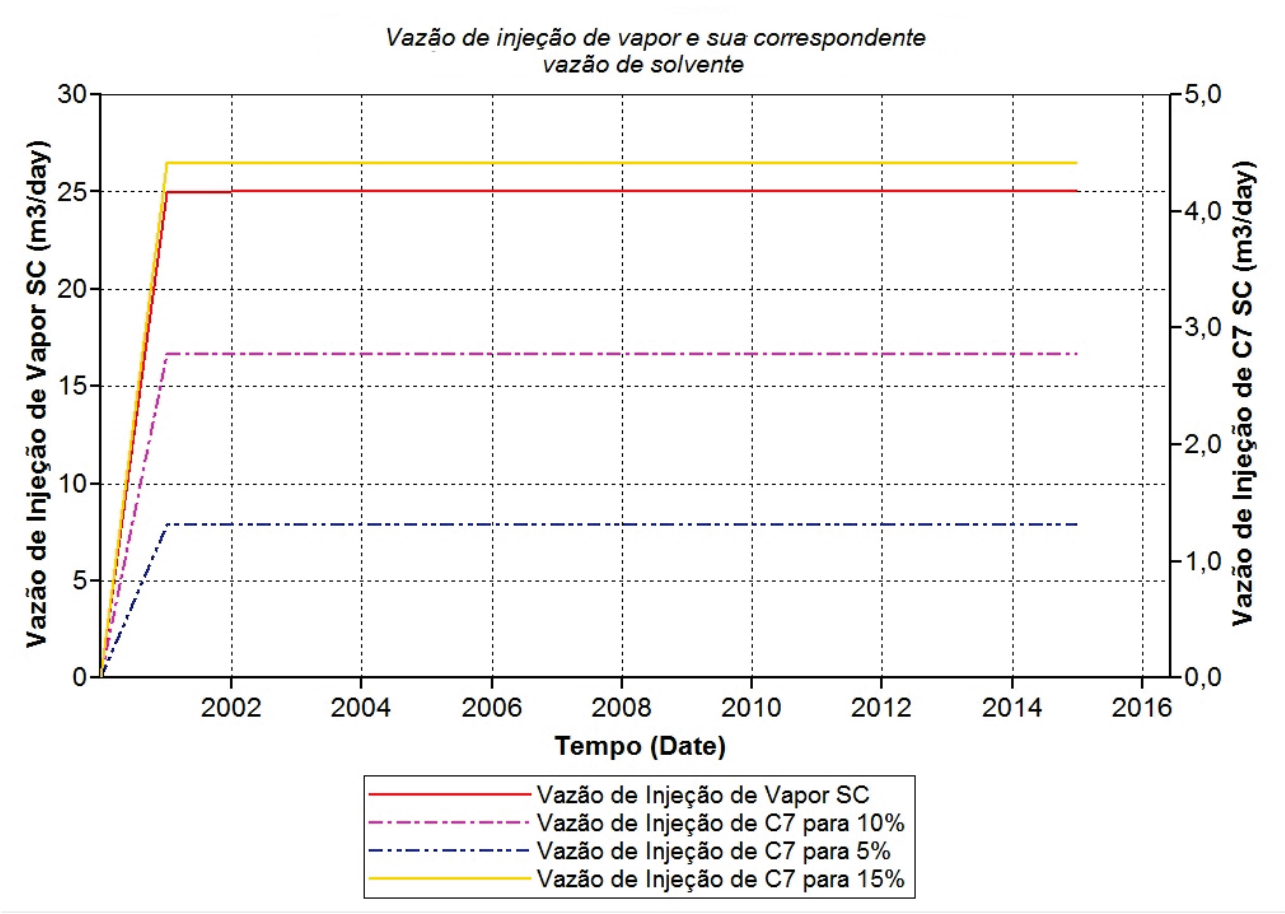

Figura 3: Vazão de injeção de vapor fixa em 25 m²/dia e vazões para as porcentagens de solvente.

A Figura 4 mostra as perdas de calor no reservatório. O tempo avança no eixo horizontal, para os anos 2, 6 e 10. Cada linha corresponde a uma porcentagem de solvente C7 (5\%,10\% e 15\%, respectivamente). A primeira Figura mostra a condição inicial do reservatório e a legenda que corresponde aos valores de entalpia, em Btu/lbmol.

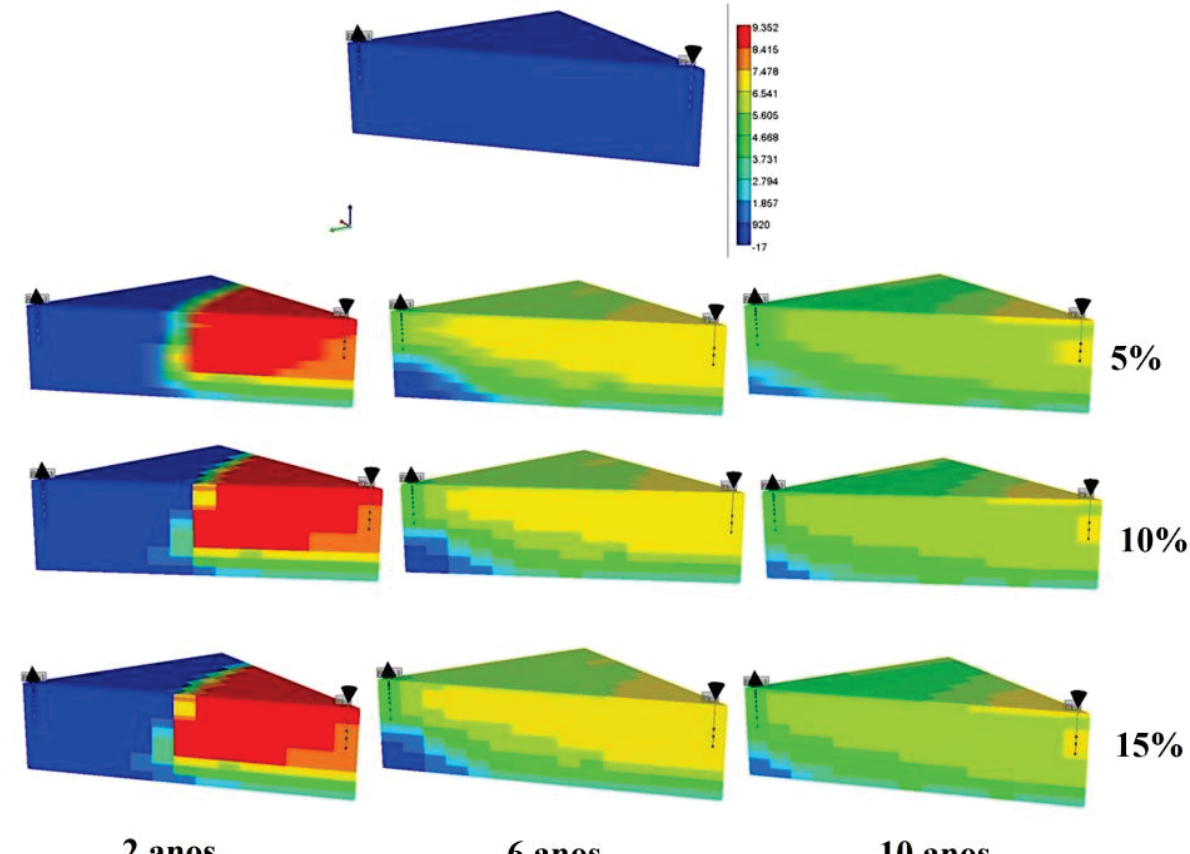

2 anos

6 anos

10 anos 
Figura 4: Perda de calor com ao longo do tempo para diferentes porcentagens de solvente

As imagens apresentam características bastante próximas, indicando pouca variação nas perdas de calor para as camadas adjacentes e sobrejacentes. No periodo inicial da injeção, podemos observar que o calor se propaga ao longo do reservatório, inclusive nas áreas inferiores.

Com o passar do tempo, podemos observar um comportamento diferente, entretanto semelhante para as diferentes porcentagens de solvente, em que o reservatório, após um período considerável de injeção, está bastante aquecido e a frente de calor, a partir de agora, se propaga através das camadas mais superficiais. De fato, a partir do breakthrough do vapor, ele passa a seguir pelo caminho preferencial (topo do reservatório), fazendo com que as áreas inferiores não sejam contempladas com o aquecimento.

A Figura 5 mostra que a quantidade de calor envolvida no sistema é a mesma para as três combinações de vazão. O incremento na vazão de solvente não implica em maiores ou menores perdas, pois a quantidade de calor analisada depende da entalpia da mistura injetada, que é constante para os três modelos. O calor usado para aquecer a mistura vapor/solvente age sobre os dois componentes (Vapor e C7), de modo que a quantidade de energia que cada mistura leva ao reservatório é praticamente a mesma, pois a capacidade calorífica da água sobrepõe-se à do solvente.

Entalpias envolvidas nas vazões de vapor e solvente estudadas

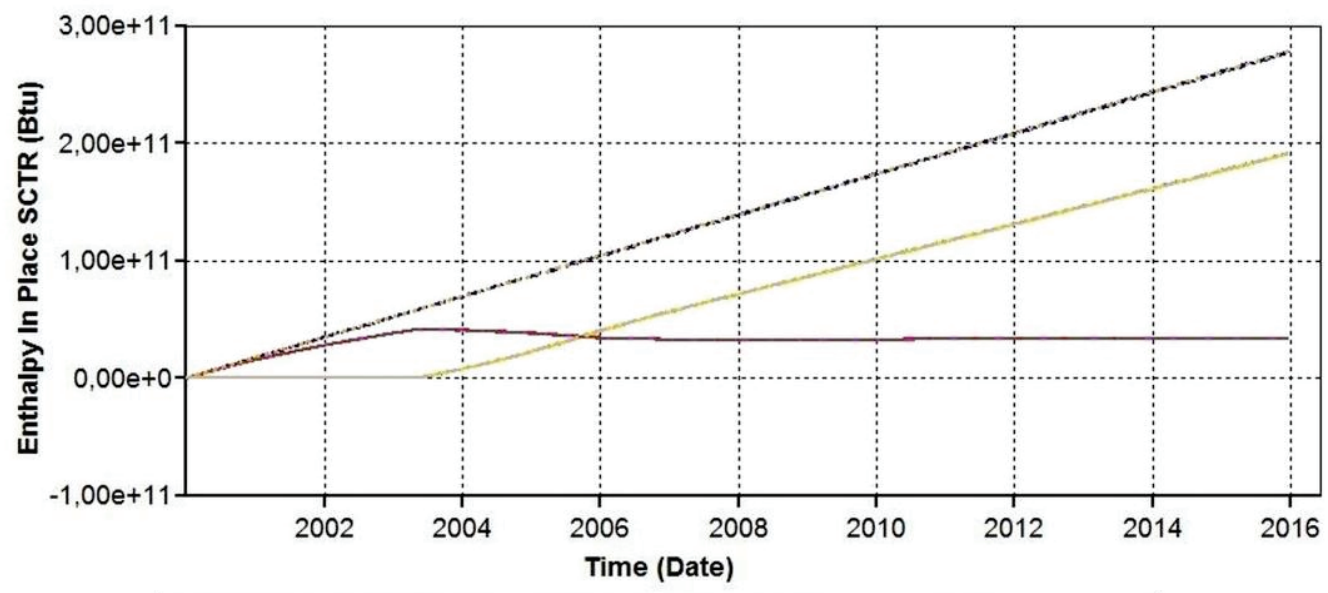

\begin{tabular}{|c|c|}
\hline 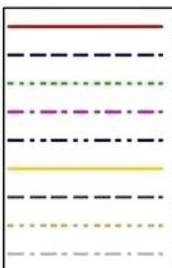 & $\begin{array}{l}\text { Entalpia in place para vazão de injeção com } 5 \% \text { de C7 } \\
\text { Entalpia injetada para vazão de injeção com } 5 \% \text { de } \mathrm{C} 7 \\
\text { Entalpia produzida para vazão de injeção com } 5 \% \text { de C7 } \\
\text { Entalpia in place para vazão de injeção com } 10 \% \text { de C7 } \\
\text { Entalpia injetada para vazão de injeção com } 10 \% \text { de C7 } \\
\text { Entalpia produzida para vazão de injeção com } 10 \% \text { de C7 } \\
\text { Entalpia in place para vazão de injeção com } 15 \% \text { de C7 } \\
\text { Entalpia injetada para vazão de injeção com } 15 \% \text { de C7 } \\
\text { Entalpia produzida para vazão de injeção com } 15 \% \text { de C7 }\end{array}$ \\
\hline
\end{tabular}


Figura 5: Entalpias envolvidas para as diferentes misturas estudadas.

Analisando a produção acumulada de óleo, a Figura 6 mostra, à esquerda, a quantidade produzida acumulada de solvente que foi injetado para as diferentes porcentagens sobre a vazão de 25 $\mathrm{m}^{3} /$ dia e a direta, a produção acumulada de óleo, descontando o valor do solvente injetado para cada porcentagem e, para comparação, a produção acumulada de óleo quando se injeta somente vapor, também para a vazão de $25 \mathrm{~m}^{3} /$ dia.
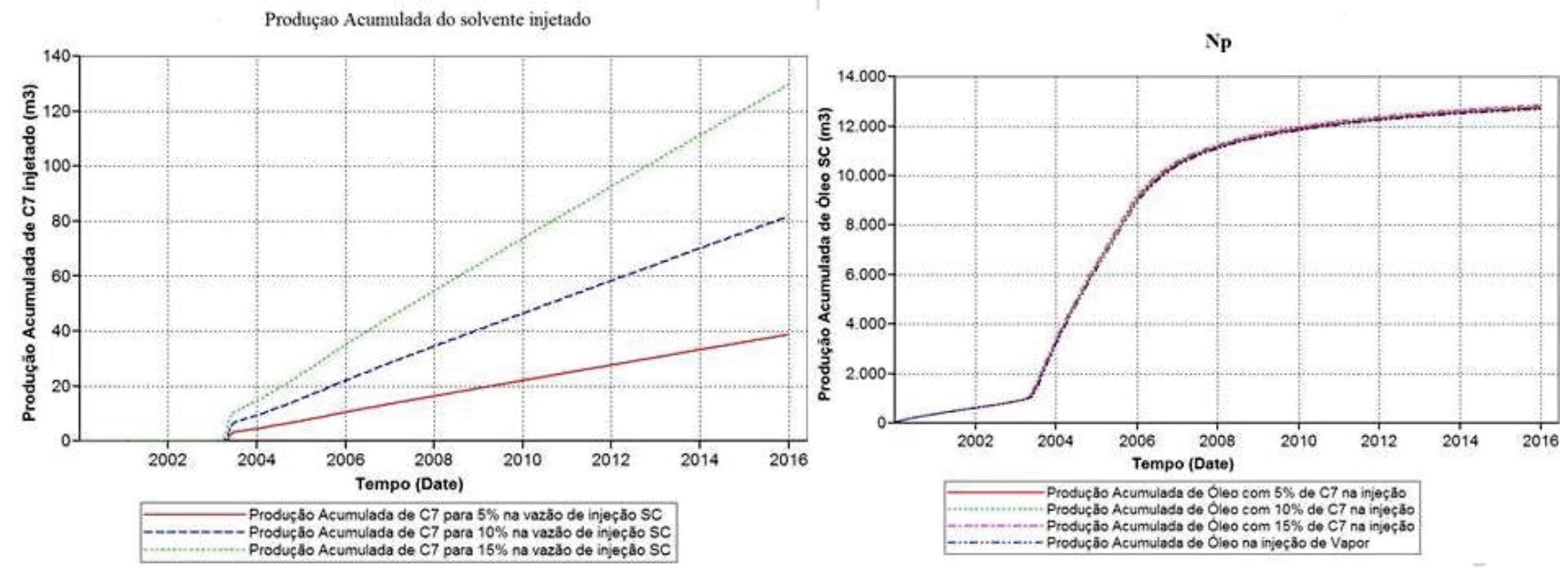

Figura 6: Produção acumulada de C7 injetado e Np líquida para diferentes vazões de injeção.

Observamos que à medida que aumentamos a quantidade de solvente na vazão de injeção, aumentamos seu valor na produção acumulada de óleo. Esse resultado já era esperado, pois apesar de uma parte do solvente ficar retida no reservatório, o seu aumento na vazão de injeção contribui diretamente na produção, uma vez que a fração retida é pequena. Vale ressaltar que essa quantidade retida foi levada em consideração nas simulações, onde o componente C7 injetado foi diferenciado do componente $C 7$ presente e produzido do reservatório.

Ao observar a produção líquida acumulada, isto é, a produção de óleo descontando a quantidade de solvente que foi produzida tem que não existe diferença expressiva quando injetamos diferentes porcentagens de solvente na vazão de injeção e somente vapor. Embora as curvas não estejam completamente sobrepostas, o incremento na produção acumulada de óleo, ao se descontar o solvente, não compensa os gastos envolvidos. Nesse caso, o solvente, apesar de ser altamente miscível com os hidrocarbonetos da reserva, não contribui de forma significativa no deslocamento do óleo. 


\section{Conclusões}

Com o modelo estudado verificou-se que:

O aumento na vazão de injeção de vapor promove um incremento nas perdas de calor para as camadas adjacentes esobrejacentes.

A partir dobreakthrough do vapor, a frente de calor passa a seguir pelo caminho preferencial (topo do reservatório), fazendo com que as áreas inferiores não sejam contempladas com o aquecimento.

A quantidade de calor perdida para as camadasadjacentes e sobrejacentesé a mesma para as três combinações de mistura solvente mais vapor. O incremento na vazão de solvente não implica em maiores ou menores perdas, pois a quantidade de calor analisada depende da entalpia da mistura injetada, queé praticamente a mesma para os três modelos.

\section{Refer ências}

ALIKHAN, ABBAS A.; FAROUQ ALI, S. M. Heavy Oil Recovery by Steam -Driven Hydrocarbon Slugs from Linear Porous Media.SPE 5019-MS. Outubro, 1974.

CMG, Computer Modelling Group LTD , 2014.

GALVÃO, E. R. V. P. Injeção de vapor e solvente como um método de recuperação avançada em reservatórios de óleo pesado. 2008. 106f. Dissertação (Mestrado em Ciência e Engenharia de Petróleo) - Centro de Tecnologia/Centro de Ciências Exatas e da Terra, Programa de Pós-Graduação em Ciência e Engenharia de Petróleo, Universidade Federal do Rio Grande do Norte, Natal.

QUEIROZ, G. O. Otimização da injeção cíclica de vapor em reservatórios de óleo pesado. 2006. 119f. Dissertação (Mestrado em Engenharia Química) - Centro de Tecnologia, Departamento de Engenharia Química, Programa de PósGraduação em Engenharia Química,Universidade Federal do Rio Grande do Norte, Natal.

ROSA, A. J.; CARVALHO, R. S.; XAVIER, J. A. D. Engenharia de reservatórios de petróleo. Rio de Janeiro: Interciência, 2006. 